\section{Berkeley's line on PWRs}

Eleanor Lawrence

THE Nuclear Laboratories at Berkeley in Gloucestershire provide the Central Electricity Generating Board (CEGB) with nuclear research facilities and expertise without parallel in any electricity utility in the western world according to CEGB Board Member Mr Donald Clark. At present, with the CEGB's controversial proposal to buy Americandesigned pressurised water reactors (PWRs) very much in the air, evaluating and verifying work on the safety of these reactors is one of Berkeley's most pressing problems.

According to Dr Bryan Edmondson, the director, very recent work by Westinghouse on the PWR pressure vessels indicates that there may be less danger than feared of the catastrophic crack propagation emphasised by opponents of PWRs. At the temperatures at which the reactors operate, defects in the steel pressure vessels would probably propagate by plastic deformation and not by sudden crack propagation. In a half-size model with 6 -inch walls (compared with 12-15-inch walls in the full-size vessel) Westinghouse tests have shown that this does in fact lead to a 'leak-before-break' situation.

Dr Edmondson emphasises that this, although comforting, is not the sort of information on which the safety case for the reactor could be based. Quality tests during manufacture, overpressure testing before service and regular inservice inspections are the best lines of defence. Also, as the vessels need not be fully pressurised until a temperature of $300^{\circ} \mathrm{C}$, they can be carefully controlled during the heating up process through temperatures at which the danger of catastrophic crack propagation is greatest. The pressure vessels are also more accessible to repair and inspection than the innards of the gascooled reactors and, as technology has been developed to deal with crack detection in those circumstances, $\mathrm{Dr}$ Edmondson is hopeful that it will not prove too big a problem with PWRs.

Commenting on the memorandum sent to the Select Committee on Science and Technology by Sir Alan Cottrell, highlighting the problems of pressure vessel safety, Dr Edmondson says that he could not disagree with Sir Alan and had been giving similar advice to the Board, but that the results of the Westinghouse tests had not been available then.

Berkeley is also evaluating the American calculations on what would happen to the pressure vessel in the case of a loss-of-coolant accident when it would be subjected to a shock of cold water.
The laboratories are now half-way through the stress analysis and so far have come up with the same reassuring answers as the Americans, whose calculations have been accepted in the safety case in the United States.

Dr Edmondson emphasises that because the PWR matter is so controversial much more evaluation and verification of already published results, which would normally be taken on trust, is having to be done. But he does not expect that the findings will differ drastically from previous work.

\section{Russia's Mars probes}

\section{from our Soviet Correspondent}

The ANNOUNCEMENT of the partial failure of the latest Soviet Mars experiment-- the probes Mars-4 to Mars-7was one of the less auspicious features of the Jubilee General Meeting of the Academy of Sciences on March 5th 1974. Already it was known that the breaking motors of Mars-4 had failed to operate so that it achieved only a close by-pass at $2,200 \mathrm{~km}$. Nevertheless some good photographs had been transmitted from Mars-4, and Mars-5 was satisfactorily in orbit investigating the planet, its atmosphere and ambient space and two further probes were still on their way.

However, Mars-6 and -7, which reached the vicinity of the planet on March 12th and 9th respectively were unable to retrieve the hopes of the programme. Although the official Tass announcement called their flight "an important step in the investigation of Mars", the news was depressing. The two probes had carried descent capsules, which would investigate the surface and relay data to the orbiting section for re-transmission. There had even been speculation (evoked by a Pravda article on future plans for planetary research) that one of them might be carrying a roving "Marsokhod". However, radio contact with the descent stage of Mars-6 was lost when it had reached "the immediate vicinity of the surface", and a failure in the on-board systems of the descent stage of Mars-7 after separation resulted in a fly-by at $1,300 \mathrm{~km}$. The "orbital" stages of these two probes apparently failed to enter aero-centric orbit, since they are reported to be "investigating the physical characteristics of space" from helio-centric orbits. So the overall design of the experiment, with four orbital stations monitoring the same data from different altitudes together with two surface probes (the previous programme used only two such stations and one surface probe), has been reduced to a single orbital station and a number of fly-by photos, valuable though these are.

The claims in the Soviet press that nevertheless valuable results have been obtained are not however merely an attempt to save face. Photometry readings, for example, have revealed a maximum precipitation of some $60 \mathrm{~nm}$ --a value several times greater than that recorded by similar instruments aboard Mars-3 in 1972, which, it is suggested may indicate a different rate of release of water vapour from the crust into the atmosphere in different regions of the planet. Traces of atmospheric ozone have been noted for the first time. The existence of the magnetic field of the planet (indicated by the data of Mars-2 and -3) has been confirmed, and readings have now been obtained for the magnetic field on the dark side of the planet.

Nevertheless, a sense of disappointment is apparent and a long article in Pravada, March 20th, on the engineering problems of designing planetary probes may well reflect not only a desire to restore public confidence but also some serious re-thinking by the planners of the "hardware" situation.

\section{ELSE in Israel}

\section{Nechemia Meyers, Rehovot}

EDIting and publishing a scientific journal is a very ordinary venture which anybody can do, and almost everybody does-at least, in the opinion of $\mathrm{Mr}$ Paul Nijhoff Asser, Secretary General of the International Group of Scientific, Technical and Medical Publishers. $\mathrm{Mr}$ Nijhoff Asser made this judgment at a recent meeting in Israel of a small but influential group of scientific communicators, the Executive Council of the European Association of Editors of Biological Periodicals (ELSE). He was commenting on a report from ELSE treasurer, Miriam Balaban, that 130,000 scientific journals are currently being produced and that the number is rising.

The European editors, who in the past have seemed anxious to demonstrate their independence of United States influences-preferring, for example, to issue their own manual of scientific writing and terminology-nevertheless invited an observer from their American counterpart organisation, the Conference of Biological Editors. Dr Karl Heumann, Executive Editor of the Federation of American Societies for Experimental Biology, took an active part in the discussions and suggested that editors should carefully consider whether to publish papers describing experiments in which the human participants were not aware of the risks they were taking.

Small though the meeting was, the Israelis present regarded it as another victory in their continuing struggle to establish their European credentials. 